\title{
Processes and experiences of Portugal's international recruitment scheme of Colombian physicians: Did it work?
}

\author{
Erika Masanet \\ Department of Sociology and Social Anthropology, Faculty of Social Sciences, Universitat de València, Av. dels Tarongers, 4b, 46021, València, Spain
}

\section{A R T I C L E I N F O}

\section{Article history:}

Received 16 April 2016

Received in revised form 20 April 2017

Accepted 9 May 2017

\section{Keywords:}

Personnel recruitment

Foreign medical doctors

Healthcare system

Portugal

Evaluation studies

\begin{abstract}
A B S T R A C T
The Portuguese Ministry of Health performed five international recruitment rounds of Latin American physicians due to the need for physicians in certain geographic areas of the country and in some specialties, as a temporary solution to shortages. Among these recruitments is that of Colombian physicians in 2011 that was the largest of the five groups. This paper presents an evaluation of the international recruitment procedure of Colombian physicians based on the criteria of procedural outcomes and health system outcomes. The methodology used is qualitative, based on semi-structured interviews with key informants and Colombian physicians recruited in Portugal and also on documentary analysis of secondary sources.

International recruitment of Colombian physicians coincided with a period of political change and severe economic crisis in Portugal that caused some problems in the course of this recruitment, mainly family reunification in the later group of Colombian physicians and non-compliance of the salary originally agreed upon. Furthermore, due to the continuous resignations of Colombian physicians throughout the 3-year contract, procedural outcomes and health system outcomes of this international recruitment were not fulfilled and therefore the expected results to meet the temporary needs for medical personnel in some areas of the country were not accomplished.
\end{abstract}

(c) 2017 Elsevier B.V. All rights reserved.

\section{Introduction}

Skilled migration of health professionals sometimes responds to active recruitment policies of states, employers or agencies. In this context, state institutions and bilateral or international agreements play an important role in the management of these migratory flows, their development and the integration conditions of these migrants in the countries of destination. Also, with growing awareness of negative effects of health professional migration on source countries, ethical codes of practices of recruitment and bilateral labour agreements have been developed since 1999 [1]. However, few countries have adopted bilateral agreements or codes for international recruitment of health professionals.

Some examples of bilateral labour agreements in the health sector outside Europe include agreements between Kenya and Namibia and between China and Signapore [2]. In Europe, the United Kingdom was one of the pioneer countries to introduce an ethical code in the international recruitment of nurses and physicians (Code of Practice for international recruitment for National Health Service employers in 2001, revised in 2004) [1-3]. The

\footnotetext{
E-mail address: erika.masanet@uv.es
}

United Kingdom developed bilateral agreements and memorandums of understanding with countries within the EU (Spain, Germany, Italy, France) as well as with non - EU countries (India, China, the Philippines, South Africa and Indonesia) [2-4]. However, bilateral labour agreements are currently losing importance worldwide in favour of other channels, such as private recruitment agencies [2].

Portugal is another European country that has resorted to international recruitment of non-EU physicians through its Ministry of Health in response to the need for physicians in certain geographical areas and the lack of family doctors [5-8]. In 2015 there were 4.7 physicians per 1000 inhabitants in the country and the evolution of this indicator has increased in the last decade (Table 1). So, rather than a problem of scarcity, there are asymmetries in the geographical distribution of physicians in the country [6]. Alentejo, autonomous regions of Açores and Madeira and Algarve are the regions with lower values in this indicator, while the North, the Centre and especially the metropolitan area of Lisbon have higher values and this unequal distribution has been maintained over time (Table 1). Family Medicine is one of the medical specialities that is lacking in Portugal, besides presenting an unequal distribution in the country. The highest percentage of users with no family doctor in October 2015 were in Regional Health Administration (RHA) of Algarve (23.5\%) and RHA of Lisbon \& Tagus Valley (19.7\%), while 
Table 1

Evolution of the number of physicians per 1000 inhabitants in Portugal by region.

\begin{tabular}{|c|c|c|c|c|c|c|c|c|c|}
\hline & 2007 & 2008 & 2009 & 2010 & 2011 & 2012 & 2013 & 2014 & 2015 \\
\hline Portugal & 3.6 & 3.7 & 3.8 & 3.9 & 4.1 & 4.2 & 4.3 & 4.5 & 4.7 \\
\hline North & 3.3 & 3.4 & 3.5 & 3.7 & 3.8 & 3.9 & 4.1 & 4.3 & 4.5 \\
\hline Centre & 3.1 & 3.1 & 3.3 & 3.4 & 3.6 & 3.8 & 3.9 & 4.1 & 4.3 \\
\hline Lisbon metropolitan area & 5.2 & 5.3 & 5.4 & 5.4 & 5.6 & 5.7 & 5.9 & 6 & 6.2 \\
\hline Alentejo & 1.9 & 2 & 2 & 2.1 & 2.2 & 2.3 & 2.4 & 2.6 & 2.7 \\
\hline Algarve & 2.9 & 3 & 3 & 3.2 & 3.2 & 3.3 & 3.4 & 3.5 & 3.7 \\
\hline Autonomous region of Açores & 1.9 & 2 & 2.1 & 2.2 & 2.3 & 2.5 & 2.6 & 2.8 & 3 \\
\hline Autonomous region of Madeira & 2.4 & 2.5 & 2.7 & 2.8 & 2.7 & 2.8 & 3 & 3.3 & 3.6 \\
\hline
\end{tabular}

Source: Health personnel statistics, Portuguese National Statistics Institute (INE).

RHAs of the North, the Centre and Alentejo had the lowest values ( $2.9 \%, 5.9 \%$ and $7.5 \%$ respectively) [9].

International recruitment of physicians has been considered by the Portuguese authorities as one of the short-term solutions to address the regional inequalities of physicians, while awaiting the results of the structural measures taken by the Ministry of Health in recent years, based on training strategies [8]. Since 2008, Portugal has performed five international recruitments of Latin American physicians: approximately 12 Uruguayan physicians in 2008 and 40 from Cuba in 2009, followed by about 85 Colombian physicians and 9 from Costa Rica in 2011, and more recently, approximately 51 Cuban physicians were recruited in 2014. The Colombian physicians group is the largest recruited in the country of origin by the Portuguese Ministry of Health, in addition to being the group whose hiring ended later (June 2014) at the time of writing this article. Therefore, it is necessary and appropriate to conduct a specific evaluation of this international recruitment in particular. There is a previous evaluation study on international recruitment practices of Uruguayan, Cuban, Colombian and Costa Rican physicians in Portugal [8]. However, this article includes a specific analysis of the recruitment of Colombian physicians and other evaluation elements.

Colombian physicians recruited by the Portuguese government arrived in two groups at different time periods in 2011: the first group arrived in March 2011 and consisted of approximately 45 Colombian physicians, and the second group arrived in June 2011 and was composed of approximately 40 physicians. The vast majority of them were general practitioners. These figures are approximate because exact number of these Colombian physicians was not made available by the Ministry of Health. However, through statistics of the newsletters of the "Foreign Human Resources in the Ministry of Health", prepared periodically by the Central Administration of the Health System of the Portuguese Ministry of Health, news of Portuguese press and data provided by the interviewees an approximate figure was ascertained. Colombian physicians were recruited to meet the needs of family doctors in various municipalities and regions of the country, namely the Lisbon metropolitan area, the Central Region of the country, the Algarve and the Açores. The duration of the employment contract was 3 years, like the rest of Latin American physicians recruited.

The socio-economic and political context in which the recruitment of Colombian physicians occurred is important to consider as factors that affected the insertion of these physicians into the Portuguese public health system. Thus, the arrival and insertion of these physicians in Portugal in 2011 coincided with the intervention in the country by the International Monetary Fund, the European Commission and the European Central Bank (the socalled "Troika"). The austerity measures imposed by the Troika resulted in a series of reforms in public services, including the Portuguese Public Health System to ensure its sustainability. The bailout by international organisations is significantly associated with the implementation of reductions in healthcare expenditure [10].
These reforms in the Portuguese Public Health System, specifically in the health workforce, resulted in salary cuts, reduction of existing staff, limiting recruitment and freezing promotions, reduced spending on overtime, extension of physicians' working hours and pay-for-performance mechanisms, among others [11]. In addition, another effect of these reforms in primary healthcare has been the increase in the number of patients per family doctor.

In Colombia, with the implementation of Law 100 of 1993, a significant increase in coverage of health care was achieved in the country [12,13], reaching $96 \%$ of the insured population in 2013 [14]. However, urban-rural and regional disparities persist in health care $[12,13]$ and the ratio of physicians per 1000 inhabitants is low (1.77 in 2013) [15], especially compared to Portugal.

The aim of this article is to provide an evaluation of the international recruitment procedure of Colombian physicians based on the distinction of two types of outcomes achieved [16]: health system outcomes and procedural outcomes. The first concerns the ability of Colombian physicians recruited to solve the problem of medical shortages and give more Portuguese citizens access to primary care. The initial objective of this recruitment was to cover some of the need for family doctors in certain regions and areas with significant shortcomings: 85 physicians recruited to attend to approximately 1800 users each, covering a total of approximately 153,000 users with family doctors. On the other hand, the procedural outcomes refer to whether Colombian physicians remained employed in the public system during the three-year period. The degree of compliance with the agreed issues between the two countries would be one of the factors to achieve this. Procedural outcomes are a necessary condition (but not enough) for health system outcomes.

To evaluate the recruitment scheme, the paper examines: a) formal aspects of recruitment (nature and characteristics of the agreement between Portugal and Colombia, institutional stakeholders, selective process and family reunification); b) reasons for the emigration of Colombian physicians; c) processes of professional integration into the Portuguese National Health System and working conditions; d) monitoring the group of Colombian physicians who remained in Portugal, once employment within the scope of the agreement is finished; and e) improvement of primary care coverage.

\section{Material and methods}

\subsection{Design and sample}

The methodology used in this research is qualitative, based on semi-structured interviews and documentary analysis of various secondary sources. As for the documentary analysis, the following secondary sources were used. First, the minutes of the meeting between the Ministry of Foreign Affairs of Colombia and the Ministry of Health of Portugal, signed on August 5, 2010 in Bogota (Colombia). In which the bases were established for the transfer of Colombian physicians to Portugal. Secondly, the document of the call for the recruitment of Colombian physicians to work in 
Table 2

Portuguese and Colombian institutional actors involved in the recruitment process.

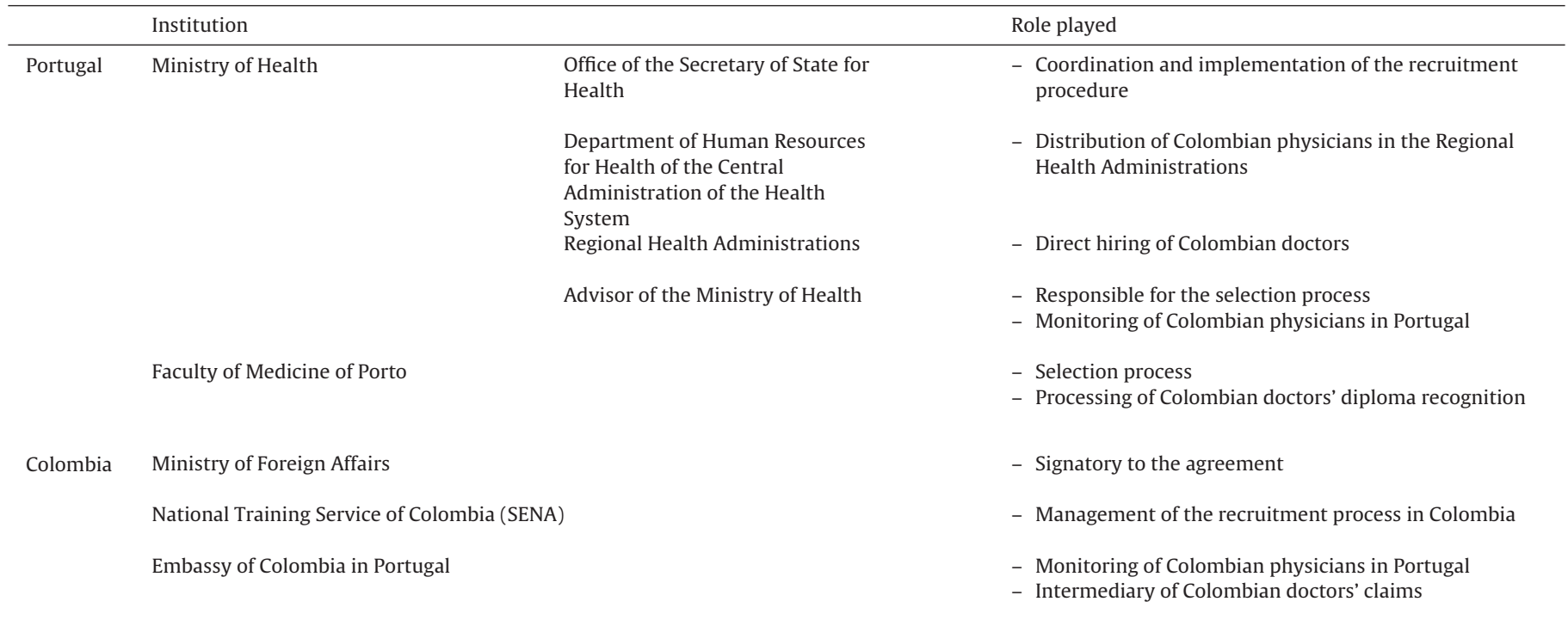

Portugal, launched by the Ministry of Social Protection and the National Training Service of Colombia (Servicio Nacional de Aprendizaje [SENA]). In this document the candidate requirements are specified, as well as the conditions of the employment offer and the selection procedure with the two stages. And finally, news related to the recruitment of Colombian physicians in the Portuguese press and websites of the Portuguese Medical Association were used.

In addition, a series of interviews were also conducted with two types of actors. On the one hand, two interviews with key informants (the former Portuguese Minister of Health and the former Portuguese Health Secretary of State) involved in the coordination and management of these procedures were carried out. The aim of these interviews was to know their opinions on management, implementation and evaluation of these contracts. On the other hand, 12 interviews with Colombian physicians were conducted. The objective of these interviews was to get their training and careers paths, issues related to the recruitment process in Portugal, professional integration processes into the Portuguese health system and prospects of permanence or return.

\subsection{Data collection}

The field work was developed in two phases. The first phase carried out between October 2011 and July 2012. The 10 interviews were conducted in the Lisbon metropolitan area because most of these physicians were recruited to work in this region. One of those interviewed specialised in Family Medicine, while the remaining nine interviewed were general practitioners. As to the basic profile of the population interviewed, 5 women and 5 men were interviewed, and ages ranged between 27 and 43 years old. Regarding the family situation, physicians interviewed were single, couples living together, married and separated/divorced, and these last two groups with or without children. The second phase carried out between August 2014 and January 2015, upon completion of the contract in the scope of the agreement (June 2014). In this phase, five of the Colombian physicians interviewed in the first phase were contacted again to update the information and only two responded to the request. Specifically, two interviews with physicians who were still in Portugal were carried out to track them and report their current situations. Data from interviews conducted in the second phase of field work have been used for Section 3.7, while data from interviews carried out in the first phase have been used for the other sections of results.

\subsection{Data analysis}

All interviews were digitally recorded with the permission of the interviewee and later transcribed verbatim or in part. The anonymity and protection of their personal data were guaranteed. A thematic qualitative analysis was performed based on the following analytical categories that correspond to the proposed objective: actors involved in the process, selection process, reasons for migration, family reunification, process of recognition on medical qualifications in Portugal, professional integration into the Portuguese health system, working conditions and prospects of staying or returning.

\section{Results}

\subsection{Features of the signed agreement and actors involved in the recruitment procedure}

The recruitment of Colombian physicians is part of an administrative agreement between the Ministry of Health of Portugal and the Ministry of Foreign Affairs of Colombia. Basically, it states that Colombian physicians will work in the health regions of Lisbon and Porto, they enjoy all the social and labour benefits provided by the legislation of Portugal on equal terms to Portuguese nationals, as well as airline tickets of the physicians (both outward and return) will be covered by the Portuguese government.

In the call disclosed in Colombia for hiring physicians to work in Portugal, the candidate requirements were specified: graduated in medicine and 3 years of professional experience in primary care in the past 5 years. Conditions of the employment offer were also specified, mainly the workplace (near to Lisbon and Porto), the contract period (between 3 and 5 years), the salary ( $€ 3200$ gross per month in 14 payments a year and food subsidy), the work day (full working day), the schedule and rest days ( 34 or $42 \mathrm{~h}$ per week, two days weekly rest, 22 days of holiday a year) and other conditions.

There are different institutional actors involved in the recruitment process (Table 2). From the Portuguese side, the Ministry of Health was the agency responsible for the recruitment, in addition to being the signatory to the agreement. Specifically, a team from 
the Office of the Secretary of State for Health was responsible for the coordination and implementation of the recruitment procedure. An advisor to the Ministry of Health was in charge of the selection process in Colombia, as well as the monitoring and accompaniment of Colombian physicians once they settled in Portugal. In addition, he acted as an intermediary between this group of physicians and the Ministry of Health. Within the Ministry of Health, the Department of Human Resources for Health of the Central Administration of the Health System was responsible for the distribution of Colombian physicians in the various RHAs. The Colombians physicians signed their employment contract with the corresponding RHAs.

The Faculty of Medicine of the University of Porto played a major role in the selection process of Colombian physicians. In addition, it was the institution where the recognition of Colombian physicians' medical diplomas was processed.

As for the actors involved in the Colombian side, although the agreement was made with the Ministry of Foreign Affairs, the government agency responsible for managing the recruitment process in Colombia was the SENA. This agency was responsible for disseminating the call of the recruitment, carried out the pre-selection of professionals and provided logistical support during the selection process by the Portuguese authorities. In addition, this institution had a role of mediation between selected physicians and the corresponding Portuguese agency for the management of various administrative procedures. For its part, the Embassy of Colombia in Portugal made the tracking of Colombian physicians in Portugal and in some cases acted as an intermediary between the group of Colombian physicians and Portuguese institutions to channel the physicians' demands.

\subsection{Reasons for the emigration of Colombian physicians}

The physicians interviewed expressed mainly two reasons why they decided to join the call of the Portuguese government recruitment: 1) the experience of working and living in another country and 2) the possibility of carrying out a medical speciality abroad (either in Portugal or in another European country, such as Spain). Other secondary reasons given by some physicians interviewed are as follows: 3) facilitating family reunification by the Portuguese government; 4) the high wages offered to them; 5) perception of a recruitment well structured and organised through SENA, generating confidence in this process.

\subsection{Selection process}

The selection process of Colombian physicians was conducted in Colombia, in which the Portuguese authorities had an important role. For this purpose, university professors of the Faculty of Medicine of Porto moved to Colombia to carry out a series of tests and exams, as well as the advisor of the Ministry of Health of Portugal in charge of this selective procedure. The selection process consisted of the following phases, each of them eliminatory:

1) Personal interview with the advisor of the Ministry of Health of Portugal.

2) Portuguese language test: this test was preceded by an intensive, month-long Portuguese course intended for preselected physicians.

3) Medical knowledge exam with two parts, a theoretical test of multiple-choice questions and an oral practical test on patients' clinical diagnoses.

Tests on the second and third phases, applied by the Faculty of Medicine as part of the selection process of Colombian physicians, are the same tests required in Portugal for foreign physicians to obtain the Medical diploma recognition. Thus, when Colombian physicians arrived in Portugal, they had already had their diploma recognition, and they needed only to register at the Portuguese Medical Association.

\subsection{Family reunification}

Family reunification was not planned formally under the recruitment procedure of Colombian physicians by the Portuguese government. However, the Portuguese authorities stated to selected Colombian physicians its intention to facilitate the process of family reunification. Thus, the Portuguese government allowed the first group of Colombian physicians who arrived in March 2011 to travel to Portugal with their families. Nevertheless, travel expenses and accommodation of their relatives were paid by the physicians themselves.

However, the second group of Colombian physicians who arrived in June 2011 had difficulties and impediments to bring their families. Unlike the first group, the second group was unable to travel with their families to Portugal (in Colombia, they were informed that physicians would travel first and soon after could bring their families). Once these physicians arrived in Portugal, they found a number of barriers to bringing their families, such that family reunification took 6 or 7 months after the arrival of these physicians to Portugal. Obstacles occurred in Immigration and Borders Service of Portugal, particularly in the issuance of necessary documents for reunification. The Embassy of Portugal in Colombia also put up many barriers in the issuance of visas for family members.

\subsection{Professional integration of Colombian physicians}

As it noted in Subsection 3.3, through tests of the selection process, Colombian physicians had already received their diploma recognition. As for the professional license to practise Medicine in Portugal, the Medical Association of Porto evaluated and processed the professional licenses of Colombians physicians. In addition, it applied the language test called "Medical Communication Exam". In general, Colombian physicians had no problems in registering at the Portuguese Medical Association.

As part of the process of professional integration into the Portuguese National Health System, Colombian physicians went through a short training period of adaptation. This training process consisted first of a 3-day course on the organisation and functioning of primary health centres, and subsequently they conducted accompaniment in medical consultations with a Portuguese doctor for 15-20 days. In this sense, most of the Colombian physicians interviewed expressed the insufficient training received to adapt fully to the new health system. Specifically, they referred to the nonexistent training in relation to legislation and protocols on health and overall functioning of the Portuguese National Health System.

According to the physicians interviewed, labour insertion was hampered by discrimination in the workplace, expressed in attitudes of indifference, hostility and rejection, by their Portuguese colleagues and superiors. According to interviewees, these situations of discrimination come from distrust of the Portuguese colleagues and superiors about their university education and experience acquired in Colombia as family doctors.

In addition, the negative statements of the Portuguese Medical Association in the national media and on its website through its magazine, claiming that these physicians did not have the speciality or the adequate knowledge to perform their work, influenced the negative perception of Portuguese physicians to Colombian physicians. Specifically, there was an initial widespread view that despite not being specialists in Family Medicine, Colombian physicians earned more than Portuguese physicians. This caused the initial 
rejection and hostility from Portuguese colleagues, that eventually softened when they conversed with Colombian physicians in their workplaces and realised they were just rumours.

\subsection{Working conditions}

Colombian physicians had a 3-year labour contract that began in March or June 2011 and ended in March or June 2014, depending on the group of Colombian physicians concerned. The labour contract was not exclusive with the Portuguese public health system; it was possible to work in other jobs outside the scope of the agreement. In fact, some Colombian physicians, after some months working in healthcare centres, combined this work with other jobs in private healthcare companies or emergency departments of public and private hospitals to increase their salary.

One of the main complaints voiced by Colombian physicians was the breach in relation to the salary originally agreed upon. The information of the call in Colombia stipulated that the salary would be $€ 3200$ gross per month. When they came to Portugal-coinciding with the economic crisis and the bailout of the country-the pay cut for civil servants was also applied to them. Thus, the salary ranged between $€ 2400$ and $€ 2800$ gross per month.

\subsection{Completion of the contract: continuity in Portugal versus returning to Colombia}

According to the agreement, Colombian physicians were to be employed until March or June 2014. However, before its completion and during the 3 years, they were producing a series of resignations of the physicians. Thus, of the approximately 85 Colombian physicians recruited by the Portuguese government, approximately 15 (18\%) completed the 3-year contract. Approximately half of the total returned to Colombia in stages during the first and second year of the contract, for personal and family reasons and the unfulfilled expectations of the contract. None of the physicians who returned were sheltered from the agreement (for example, return airline tickets were not paid) because all of them returned before the contract ended and therefore they did so independently. According to the physicians interviewed, physicians who returned managed to rejoin the workforce quickly. The other physicians remained in Portugal, and the majority of them are reported to be doing a medical speciality. A minority renewed their contract in the health centres once completed-but not in the scope of the agreement-or are working independently in medical services companies they created, along with other physicians who are performing specialities.

Colombian physicians who remained in Portugal to do the speciality, reportedly gave up their jobs during the first and second year of the contract. In fact, the medical speciality training was one of the objectives for which Colombian physicians came to Portugal (see Section 3.2). The physicians' decision to give up their contract to begin a medical speciality created discomfort among some Portuguese authorities involved in this recruitment. On the other hand, given the reduction in the salaries of medical residents, some of these Colombian physicians who are doing a speciality, along with some physicians who completed the 3-year contract and did not want to continue, decided to join together to create their own medical services companies to supplement their salaries.

\section{Discussion}

The arrival and labour insertion of Colombian physicians in Portugal in 2011 coincided with a period of political and institutional change in the country, in addition to occurring in an increasingly adverse financial and economic context. This period of change did not favour a positive course for the integration process of Colombian physicians. In addition, the entry of a new government in June 2011, which had not signed the agreement and had not made all previous management recruitment procedures, triggered in an attitude of certain passivity towards the situation of this large group of recruited physicians. Specifically, this government change led to bureaucratic obstacles in family reunification of the second group of physicians who arrived to Portugal in June 2011. To this should be added the implementation of austerity policies and salary cuts that also affected the group of Colombian physicians. This caused widespread discontent at unfulfilled salaries agreed in the country of origin, being the main banner of struggle of the Colombian physicians.

The results of the research allow evaluating this practise of international recruitment through the criteria of procedural outcomes and health system outcomes. Firstly, procedural outcomes is influenced by two factors: 1 ) the breach of salary agreed in the country of origin which caused widespread disappointment and frustration among Colombian physicians; 2) the aspiration of many of these physicians to perform a medical speciality in Portugal. In this regard, it is important to note the enormous difficulties for the medical speciality in Colombia, given the unique characteristics of specialist training system in the country: no pay during training, coupled with the fact that physicians have to pay fees to do it, and the limited number of positions available. In addition, during the course of the speciality, physicians cannot work to afford it. Therefore, the possibility of a medical speciality in Portugal, after completion of the contract, attracted many Colombian physicians to join the call. These two factors led to the vast majority of Colombian physicians to renounce the contract long before completion, either to return to their country or to perform medical speciality. Thus, of the total Colombian physicians hired, less than one in five (approximately 15 out of 85) completed the 3-year contract. So, procedural outcomes of this international recruitment were not fulfilled.

Secondly, the criteria of health system outcomes were not accomplished because procedural outcomes are a necessary condition for this criteria. Thus, the expected results of this international recruitment were to get 153,000 users to be attended by family doctors, and consequently improve access to primary care of the Portuguese population. However, with the continuous resignations of Colombian physicians during the first and second year of the contract, the results obtained were closer to 27,000 users who had access to family doctors for the duration of the recruitment scheme (1800 users for each of the 15 Colombian physicians completing the 3-year contract). This figure was away from the initial objective, so health system outcomes were not achieved. Nevertheless, the above figure indicates that this recruitment supposed some benefits for the Portuguese Health System and for patients.

From the perspective of the country of origin, the international recruitment of Colombian physicians did not bring benefits to the Colombian health system and aggravated a little more the problem of shortage of physicians in the country. In this sense lies the dilemma between individual freedom of Colombian physicians based on the right to migrate or to develop professionally through conducting a medical speciality, and the collective right to primary care of the Colombian or Portuguese population. However, it is true that this collective right falls under the responsibility of the State. On the other hand, the culture of medical schools in most of the global South is more focused on market demand in developed countries and thus on acquiring highly specialised skills than in the health needs of its population [17]. This medical culture is also predominant among Colombian physicians, aspiring to do a medical speciality as the realisation of a significant professional accomplishment in their careers. 
Finally, discrimination perceived by physicians interviewed in their workplace was an element that hindered their reception and labour integration into healthcare centres. This discriminatory treatment, which can be rooted in prejudice for being a foreign doctor, in some cases acted as a barrier to good professional performance in their workplaces. Other research in the Portuguese $[18,19]$ and European context [20-22] also confirm the discrimination that immigrant physicians face in their workplace. The highly protectionist stance of the Portuguese Medical Association contributed to this climate of initial hostility towards Colombian physicians. In fact, this organisation showed from the beginning its opposition to the recruitment strategy of Latin American physicians recruited by the Portuguese government. It argued the existence of alternatives to encourage the retention of Portuguese physicians in these jobs.

The study has four limitations. First, the limited number of Colombian doctors interviewed. Second, the monitoring group of Colombian physicians who returned to their country, especially in terms of professional reintegration, has not been possible to perform in this study. Third, the article focuses mainly on the perspective of the recipient country because the field work took place in Portugal. And fourth, the study does not cover the user perspective - Portuguese patients' experience with foreign-trained doctors could have been relevant.

\section{Conclusions}

This experience of international recruitment of physicians in Portugal provides learning and some reflections and recommendations for new recruitment experiences. Firstly, the country of destination should have considered the ethical principle based on avoiding active recruitment of health personnel from developing countries facing shortages of health workers, as well as the principle of non-discrimination of foreign health professionals, both of which are included in the WHO Global Code of Practice on the international recruitment of health personnel [23]. Secondly, regarding the salary breach, a greater communication between the group of Colombian physicians and the Portuguese authorities based on honesty about the socioeconomic situation in the country, would have helped to minimise discontent and frustration of physicians. In addition, this shows how the conditions for international recruitment and migration change with the broader economic and political context; this is what makes migration volatile and unpredictable and, therefore, complex for researchers and policy-makers [24].

Thirdly, the agreement between the two countries should have taken into consideration the aspiration of most of the Colombian physicians to perform medical specialities abroad. Thus, some sort of consensus could have been reached that would have benefited both the physician group and the Portuguese State, saving the discomfort created around the physicians' decision to give up their contract to begin a medical speciality. In this regard, in future international recruitments it would be advisable to establish a prior dialogue and negotiations between the authorities of the host country and representatives of foreign physicians on the expectations of both parties.

Finally, it is necessary to create spaces for the engagement and dialogue of stakeholders - such as the Ministry of Health, professional associations, unions of health professionals, representatives of users - to discuss the best strategies to address the need for physicians in some medical specialities and their geographical imbalances in the country. The growing trends, in recent years, in the emigration of Portuguese health professionals and in the outflows of Portuguese youngsters to study medicine abroad [7] should also be taken into consideration. This dialogue is essential for the creation of policy for the health professionals and health policies that are capable of ensuring an equitable access for the Portuguese population to health services.

\section{Conflict of interest}

None to declare.

\section{Acknowledgments}

This study was part of the postdoctoral project "Skilled migration of health professionals in Portugal and Spain: a comparative study on the conditions of integration into the host society", funded by the Portuguese Foundation for Science and Technology (FCT), Ministry of Education and Science of Portugal. The author is grateful to the Colombian doctors and key informants interviewed, and the entities that provided information and documentation. The author is also grateful to the editor Irene A. Glinos as well as the anonymous reviewers, whose comments improved the final version of the article.

\section{References}

[1] Connell J, Buchan J. The impossible dream? Codes of practice and the international migration of skilled health workers. World Medical and Health Policy 2011;3(3):1-17, http://dx.doi.org/10.2202/1948-4682.1175.

[2] Plotnikova E. The role of bilateral agreements in the regulation of health worker migration. In: Buchan J, Wismar M, Glinos IA, Bremner J, editors. Health professional mobility in a changing Europe. New dynamics, mobile individuals and diverse responses. Volume II. Observatory Studies Series (32). Copenhagen: World Health Organization; 2014. p. 325-44. Available at: http://www.euro.who.int/__data/assets/pdf_file/0006/248343/HealthProfessional-Mobility-in-a-Changing-Europe.pdf (Accessed 24 February 2017).

[3] Buchan J, McPake B, Mensah K, Rae G. Does a code make a difference - assessing the English code of practice on international recruitment. Human Resources for Health 2009;7(33), http://dx.doi.org/10.1186/1478-4491-7-33.

[4] Buchan J. International recruitment of nurses: policy and practice in the United Kingdom. Health Research and Educational Trust 2007;42(3):1321-35.

[5] Dussault G, Conceição C. National profile of migration of health professionals-Portugal. Mobility of Health Professionals Project (MoHProf)-National Report for Portugal. Brussels: European Commission; 2012.

[6] Russo G, Ferrinho P, De Sousa B, Conceição C. What influences national and foreign physicians' geographical distribution? An analysis of medical doctors' residence location in Portugal. BMC Human Resources for Health 2012;10(12), http://dx.doi.org/10.1186/1478-4491-10-12.

[7] Ribeiro J, Conceição C, Pereira J, Leone C, Mendonça P, et al. Health professionals moving to... and from Portugal. Health Policy 2013;114(2-3):97-108, http://dx.doi.org/10.1016/j.healthpol.2013.05.009.

[8] Masanet E. Reclutamiento de inmigrantes cualificados: el caso de la contratación en origen de médicos latinoamericanos en Portugal. In: Cairo H, Finkel L, editors. Crisis y cambio: propuestas desde la Sociología. Actas del XI Congreso Español de Sociología. Madrid: Federación Española de Sociología, Universidad Complutense de Madrid; 2014. p. 993-1001. Available at: http://www.fes-sociologia.com/files/congress/11/ Libro\%20de\%20Actas\%20Adenda.pdf (Accessed 08 October 2015).

[9] Administração Central do Sistema de Saúde. Publicação periódica sobre o número de utentes inscritos nos cuidados de saúde primários. Outubro 2015. Lisboa: Administração Central do Sistema de Saúde; 2015. Available at: http:// www.acss.min-saude.pt/Portals/0/Rel_CSP_OutubroVF\%20(2).pdf (Accessed 08 September 2016).

[10] Reeves A, McKee M, Basu S, Stuckler D. The political economy of austerity and healthcare: cross-national analysis of expenditure changes in 27 European nations 1995-2011. Health Policy 2014;115:1-8, http://dx.doi.org/10.1016/j.healthpol.2013.11.008.

[11] Correia T, Dussault G, Pontes C. The impact of the financial crisis on human resources for health policies in three southern-Europe countries. Health Policy 2015;119(12):1600-5, http://dx.doi.org/10.1016/j.healthpol.2015.08.009.

[12] Agudelo CA, Cardona J, Ortega J, Robledo R. Sistema de salud en Colombia: 20 años de logros y problemas. Ciencia \& Saúde Coletiva 2011;16(6):2817-28, http://dx.doi.org/10.1590/S1413-81232011000600020.

[13] Ayala J. La salud en Colombia: más cobertura pero menos acceso. Documentos de trabajo sobre Economía Regional no. 204. Cartagena: Banco de la República; 2014. Available at: http://www.banrep.gov.co/sites/default/files/ publicaciones/archivos/dtser_204.pdf (Accessed 10 September 2016).

[14] Beltrán YA, Garzón IJ, Vallbuena PN. Estimación del indicador de prestación del servicio de salud en Colombia (2007-2010); una base para la discusión sobre 
calidad de vida. Cuadernos Latinoamericanos de Administración 2013;IX(16), 79.100.

[15] Ministerio de Salud y Protección Social. Indicadores básicos, 2014. Situación de salud en Colombia. Bogotá: Ministerio de Salud y Protección Social; 2015. Available at: https://www.minsalud.gov.co/sites/rid/Lists/BibliotecaDigital/ RIDE/VS/ED/PSP/Indicadores-basicos-salud-2014.pdf (Accessed 10 September 2016).

[16] Knoepfel P, Larrue C, Subirats J, Varone F. Análisis y gestión de políticas públicas. Barcelona: Ariel; 2008.

[17] Huish R. How Cuba's Latin American School of Medicine challenges the ethics of physician migration. Social Science and Medicine 2009;69(3):301-4, http://dx.doi.org/10.1016/j.socscimed.2009.03.004.

[18] Ribeiro JS. Migration and occupational integration: foreign health professionals in Portugal. In: Kuhlmann E, Saks M, editors. Rethinking professional governance: International directions in health care. Bristol: The Policy Press; 2008. p. 201-15.

[19] Romero C, Masanet E. Contratación internacional de médicos/as latinoamericanos/as en Portugal y España. Forum Sociológico 2016;27:53-60, http://dx.doi.org/10.4000/sociologico.1328.
[20] Freire A, Masanet E. Médicos latinoamericanos en Cataluña: procesos de integración y desarrollo profesional. Revista Interdisciplinar de Mobilidade Humana-REMHU 2013;41:225-40.

[21] Wolanik K, Öhlander M. A troubled elite? Stories about migration and establishing professionalism as a Polish doctor in Sweden. Working Papers-Center on Migration, Citizenship and Development (COMCAD) no. 110. Bielefeld: COMCAD; 2012.

[22] Cooke L, Halford S, Leonard P. Racism in the medical profession: the experience of UK Graduates. London: British Medical Association, Health Policy and Economic Research Unit; 2003.

[23] WHO. WHO Global Code of Practice on the International Recruitment of Health Personnel. Geneva: World Health Organization (63rd World Health Assembly, WHA63.16); 2010. Available at: http://www.who.int/hrh/migration/code/ WHO_global_code_of_practice_EN.pdf (Accessed 28 June 2016).

[24] Glinos IA. Health professional mobility in the European Union: exploring the equity and efficiency of free movement. Health Policy 2015;119(12):1529-36, http://dx.doi.org/10.1016/j.healthpol.2015.08.010. 